O.B.Скороходкина ${ }^{1}$, А.В.Лунцов ${ }^{2}$

\title{
Значимость специфического аллергологического обследования как этапа диагностического процесса при верификации бронхиальной астмы у подростков и юношей призывного возраста
}

1 - ГОУ ВПО "Казанский государственный медицинский университет Росздрава": 420012, Республлка Татарстан, Казань, ул. Бутлерова, 49

2 - ГУЗ "Республиканская клиническая больница" МЗ РТ: 420064, Республика Татарстан, Казань, Оренбургский тр-т, 138

\section{O.V.Skorokhodkina, A.V.Luntsov}

\section{Importance of specific allergological examination as a part of diagnostic workup in asthmatic adolescents and young men of recruiting age}

\begin{abstract}
Summary
Diagnosis of asthma, especially mild asthma, in adolescents and young men of recruiting age is challenging and requires complex diagnostic approach. To assess the diagnostic value of different allergological methods we examined 343 patients referred by military recruiting offices to confirm diagnosis of asthma. Analysis of allergy history, results of allergy skin tests with non-infectious allergens and laboratory data allowed detection of specific hypersensitivity in $90.9 \%$ of adolescents and young men. Comprehensive allergological examination of 115 patients included challenge tests with inhaled allergen, which were highly safe and diagnostic.

Key words: bronchial asthma, men of recruiting age, allergological examination, challenge tests with inhaled allergen.
\end{abstract}

\section{Резюме}

Диагностика бронхиальной астмы (БА), особенно ее легких форм, у подростков и юношей призывного возраста может вызывать трудности и требовать применения комплекса диагностических исследований. С целью оценки информационной значимости различных этапов аллергологического обследования в программе верификации БА были обследованы 343 пациента, направленные военкоматами для уточнения диагноза. Результаты анализа аллергологического анамнеза, кожного тестирования с неинфекционными аллергенами и лабораторных методов диагностики позволили выявить специфическую гиперчувствительность у $90,9 \%$ подростков и юношей. У 115 пациентов углубленное аллергологическое обследование включало в себя постановку ингаляционных провокационных проб с аллергенами, которые продемонстрировали высокую безопасность и диагностическую значимость.

Ключевые слова: бронхиальная астма, лица призывного возраста, аллергологическое обследование, ингаляционные провокационные пробы с аллергенами.

Бронхиальная астма (БА) в настоящее время - заболевание с хорошо изученными и описанными клиническими, известными физиологическими и морфологическими особенностями. Понимание основных звеньев патогенеза и факторов риска БА позволило сформулировать основные диагностические подходы к верификации данной патологии, которые предполагают наряду с выявлением характерной клинической картины постановку тестов, направленных на фиксацию эпизодов бронхиальной обструкции с последующим доказательством ее обратимости и вариабельности [1]. Однако не менее важным в ходе диагностического поиска является установление возможного причинно-значимого фактора развития заболевания, в первую очередь - роль экзогенных аллергенов, что может быть реализовано в результате проведения специфического аллергологического обследования.

Таким образом, оценка аллергологического статуса позволяет уточнить этиологию заболевания, при этом проведение ингаляционного провокацион- ного тестирования (ИПП) с аллергеном применяется и для диагностики самой нозологической формы атопической БА [1, 2].

Особую значимость приобретает проблема диагностики БА в подростковом возрасте, что неотъемлемо связано с медицинским освидетельствованием призывников. Известно, что в этом возрастном периоде наблюдается преобладание легких форм заболевания, сопровождающегося частыми и длительными ремиссиями, что осложняет постановку диагноза БА [3]. В этих условиях особое значение при верификации диагноза у данной категории больных имеет проведение комплексного обследования с осуществлением не только функциональных тестов, но и углубленного аллергологического обследования [4].

Целью нашего исследования явилась оценка информационной значимости проведения комплекса методов специфического аллергологического обследования и определение места ИПП с аллергенами в диагностическом алгоритме при верификации БА у подростков и юношей призывного возраста. 


\section{Материалы и методы}

Для решения поставленных задач на базе Республиканского центра клинической иммунологии МЗ РТ были обследованы 343 подростка и юноши, направленные военкоматами Республики Татарстан с целью верификации диагноза БА. Средний возраст пациентов составил $16,8 \pm 0,4$ лет.

Диагноз заболевания устанавливался на основании комплекса исследований, предусмотренных медицинскими стандартами диагностики и лечения больных БА $[1,2]$. Согласно указанным документам, всем пациентам осуществлялось обязательное общеклиническое обследование, в т. ч. исследование функции внешнего дыхания (ФВД) с проведением теста с $\beta_{2}$-адреномиметиком. Прирост объема форсированного выдоха за 1-ю с $\left(\mathrm{OФВ}_{1}\right)$ на $\geq 12 \%$ (или $\geq 200$ мл) по сравнению с исходными значениями принимался как диагностически значимый.

С целью диагностики синдрома бронхиальной гиперреактивности (БГР) у 97 (28,3 \%) пациентов с нормальными показателями ФВД осуществлялся комплекс исследований, включавший в себя постановку теста с дозированной физической нагрузкой и ингаляционных проб с фармакологическими агентами: гистамином и гипертоническим раствором хлорида натрия (4,5\%). Таким образом, тест с физической нагрузкой был выполнен 67 пациентами. В случае отрицательного результата теста с физической нагрузкой (у 43 больных) были проведены ингаляционные пробы с фармакологическими агентами. Бронхомоторные тесты осуществлялись в соответствии с рекомендациями экспертов Европейского респираторного общества [5].

Специфическое аллергологическое обследование на амбулаторном этапе проводилось всем больным по стандартной программе [1], которая включала в себя анализ данных аллергологического анамнеза, проведение кожного тестирования с аллергенами и лабораторных методов.

Кожное тестирование проводилось больным с отягощенным аллергологическим анамнезом в период ремиссии заболевания при отсутствии соответствующих противопоказаний. Для постановки кожных проб использовался стандартный набор диагностических аллергенов, включающих в себя группу бытовых, эпидермальных (производства АО "Биомед" им. И.И.Мечникова, Москва) и пыльцевых (производства Ставропольского НИИ вакцин и сывороток) аллергенов в стандартной концентрации 10000 PNU. Для постановки кожных проб применялся скарификационный и, по показаниям, внутрикожный метод тестирования.

Лабораторные методы аллергологического обследования включали в себя определение уровня общего и специфических IgE в сыворотке крови у 65 пациентов методом иммуноферментного анализа (ЗАО "ДИАплюс", Москва).

ИПП с аллергенами проведены у 115 подростков и юношей с выявленной специфической гиперчувствительностью, имевших нормальные показатели ФВД. Обследование проводилось в условиях ста- ционара. Использовались диагностические аллергены домашней пыли или Dermatophagoides pteronyssinus производства АО "Биомед" им. И.И.Мечникова (Москва). ИПП осуществлялись по модифицированному протоколу в соответствии с рекомендациями Европейского респираторного общества и методик, предложенных отечественными авторами [5]. Протокол ИПП включал в себя проведение 3 последовательных ингаляций аллергена в дозе 10, 100, $1000 \mathrm{PNU}$ / мл длительностью 2 мин с интервалом в 60 мин с использованием струйного небулайзера Omron. Оценку результатов проводили на каждом этапе после ингаляций по динамике субъективных жалоб пациента, аускультативной картины, а также по результатам измерений показателей ФВД: диагностически значимым считалось снижение ОФВ и пиковой объемной скорости выдоха (ПОС) на $\geq$ $15 \%$ по сравнению с исходными показателями, возникновение аускультативных симптомов бронхиальной обструкции. Наблюдение за пациентами с целью фиксации отсроченных реакций после ингаляции аллергена, с проведением пикфлоуметрии и исследования ФВД, проводилось в течение 24 ч после завершения теста.

Математическая обработка полученных результатов осуществлялась с использованием программы Statistica for Windows 6.0, оценка достоверности различий относительных величин выполнялась с использованием $\chi^{2}$-критерия. Вероятность различий в группах считалась статистически значимой при $p<0,05$.

\section{Результаты и обсуждение}

Анализ полученных результатов показал, что у $51,3 \%$ больных диагноз БА был верифицирован на основании данных обязательных исследований, позволивших выявить синдром обратимой бронхиальной обструкции в тесте с $\beta_{2}$-адреномиметиком (рисунок).

В тоже время почти у половины обследованных пациентов призывного возраста (167 человек $48,7 \%)$, при наличии характерных жалоб и других данных анамнеза, на момент осмотра отсутствовали объективные признаки бронхиальной обструкции и регистрировались нормальные показатели ФВД, что для установления или подтверждения диагноза БА

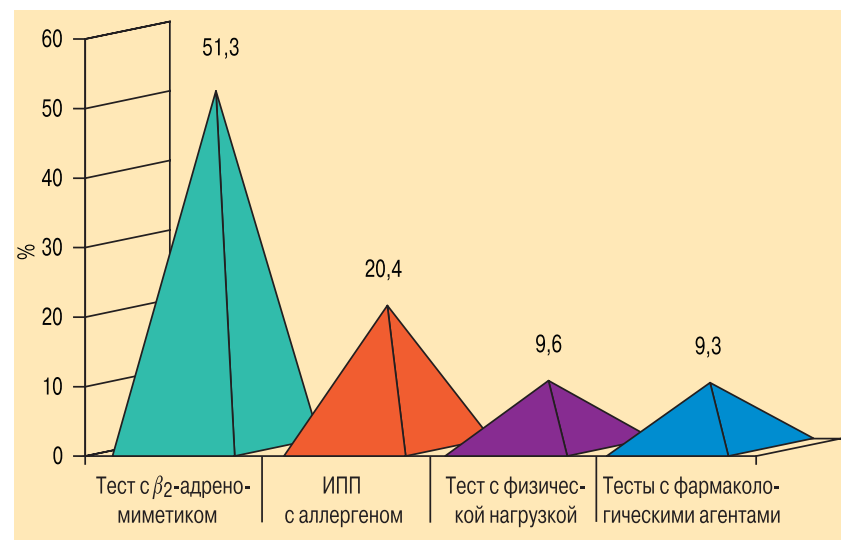

Рисунок. Распределение случаев БА в соответствии с проведенными тестами, направленными на верификацию заболевания 
потребовало проведения углубленного обследования, предусматривающего постановку дополнительных диагностических тестов, часть из которых были направлены на выявление синдрома БГР, являющегося обязательной составляющей патогенеза БА.

С этой целью у 97 подростков и юношей, имеющих нормальные показатели ФВД и отрицательные результаты проведенного аллергологического обследования, были выполнены пробы с физической нагрузкой и фармакологическими агентами: гистамином и гипертоническим раствором хлорида натрия.

Анализ полученных результатов показал, что положительные результаты тестов имели диагностическую значимость у 52 (53,6 \%) больных. Результаты пробы с физической нагрузкой явились информативными для верификации БА в 34,3 \% случаев. Сравнительный анализ результатов ингаляционных тестов с фармакологическими агентами обнаружил достоверно более высокую чувствительность пробы с гистамином (74,3\%), по сравнению с тестом с гипертоническим раствором хлорида натрия $(45,5 \% ; p<0,001)$.

Отдельным этапом в диагностическом процессе явилось проведение комплексного аллергологического обследования, которое позволяло в ряде ситуаций определить этиологию БА и, следовательно, адекватно сформулировать не только элиминационные мероприятия, но и спланировать терапевтические подходы, включая проведение специфической иммунотерапии аллергенами.

Результаты проведенного аллергологического обследования позволили выявить наличие специфической гиперчувствительности у 90,9\% $(p<0,001)$ пациентов: в подавляющем большинстве случаев к группе бытовых аллергенов $(97,4 \%$; $p<0,001)$, peже - к аллергеном пыльцы растений, эпидермальным аллергенам.

При этом у больных, имевших сенсибилизацию к группе бытовых аллергенов, в большинстве случаев отмечалось выявление повышенной чувствительности к аллергенам домашней пыли $(96,5 \%)$ и Dermatophagoides pteronyssinus $(84,3 \%)$. При отрицательных результатах скарификационных проб у 115 $(38,6 \%)$ больных осуществлялось внутрикожное тестирование с группой бытовых аллергенов: домашней пыли и / или D. pteronyssinus. Специфическая гиперчувствительность к группе бытовых аллергенов выявлена у 97,4 \% пациентов: по результатам скарификационного тестирования - у 64,1 \%, внутрикожных проб - у 35,9 \% больных.

В случае наличия сенсибилизации к аллергенам животных чаще отмечалась повышенная чувствительность к аллергену шерсти кошки (10,2 \%), а в группе больных, сенсибилизированных пыльцевыми аллергенами, в 33,6 \% случаев наблюдалась гиперчувствительность к пыльце луговых и в 47,8 \% - к пыльце сорных трав.

Анализ частоты выявления сочетанных форм специфической гиперчувствительности показал, что у обследованных подростков и юношей преимущественно выявлялась моносенсибилизация (65,5\%; $p<0,001)$, чаще - к группе бытовых аллергенов, не- сколько реже - сочетанная сенсибилизация к $\geq 2$ $(30,1 \%)$ группам аэроаллергенов $(5,6 \%)$.

Результаты анализа проведенного аллергологического обследования in vitro показали у пациентов с верифицированной БА значимое повышение уровня общего IgE, который отличался от нормальных значений у 87,6 \% ( $p<0,001)$ больных. При этом значение уровня общего IgE имело определенную зависимость от степени тяжести заболевания. Так, у пациентов, имеющих персистирующую БА тяжелого или среднетяжелого течения, отмечалось более частое выявление очень высокого уровня общего $\mathrm{IgE}$ $(47,8 \% ; p<0,05)$, при этом в группе подростков и юношей с наличием интермиттирующей БА часто (у $39,5 \%$ ) определялся нормальный уровень общего $\mathrm{IgE}$. Специфический $\mathrm{IgE}$ в группе обследованных пациентов выявлялся в 47 \% случаев.

Таким образом, положительные результаты приведенных тестов аллергодиагностики in vivo и in vitro позволяют выявить наличие специфической гиперчувствительности к определенным аллергенам и в совокупности с характерными изменениями ФВД дают возможность не только установить диагноз БА, но и обозначить этиологию заболевания.

В тоже время следует признать, что в случаях, когда показатели ФВД соответствуют должным величинам, положительные результаты кожных проб и высокий уровень общего и специфического IgE подтверждают исключительно наличие сенсибилизации, однако верифицировать диагноз самой нозологической формы БА не представляется возможным. У этой категории пациентов эффективным в диагностике является постановка ИПП с аллергенами, которая позволяет не только зафиксировать наличие бронхообструктивного синдрома, но и подтвердить причинно-следственную взаимосвязь нарушений бронхиальной проходимости и ингаляции конкретного аллергена.

Анализируя данные литературны, касающиеся этой проблемы, следует отметить, что в соответствии с клиническими рекомендациями, разработанными отечественными авторами [1], ограничений для проведения ИПП, при отсутствии противопоказаний, нет, хотя при этом констатируется факт, что данное исследование в настоящее время проводится достаточно редко. В свою очередь современные международные согласительные документы [2] не рекомендуют ИПП для широкого применения в клинической практике, мотивируя это возможностью развития при их выполнении угрожающего жизни бронхоспазма. В то же время значительный ряд оригинальных исследований доказал высокую специфичность и воспроизводимость теста, его целесообразность и безопасность для использования при определенных показаниях, в т. ч. в рутинной клинической практике [6].

В связи с этим была сформирована группа из 115 пациентов с выявленной специфической гиперчувствительностью, характерным анамнезом заболевания и отсутствием обструктивных изменений ФВД, которым было осуществлено ингаляционное провокационное тестирование с аллергенами. В 73,9 \% 
случаев проводилась ИПП с аллергеном домашней пыли, в 26,1\% - с аллергеном D. pteronyssinus. У 70 больных отмечались положительные результаты пробы, а следовательно, чувствительность данного теста в диагностике БА оказалась достаточно высокой и составила 60,9\%.

Анализ случаев положительных результатов ИПП с аллергенами показал различную информационную значимость критериев возникновения диагностически значимой бронхиальной обструкции после ингаляции аллергена. Наименьшей информативностью для оценки результатов обладали субъективные данные: у 34,4 \% пациентов в случаях положительных результатов жалобы на наличие затрудненного дыхания отсутствовали $(p<0,001)$. При этом возникновение аускультативных симптомов в виде сухих свистящих хрипов было отмечено у всех пациентов. Информационная значимость различных показателей ФВД также отличалась (таблица).

Несколько чаще (в 76,2 \% случаев) выявлялось диагностически значимое снижение ОФВ 1 , при этом подобные изменения ПОС фиксировались у 68,5 \% подростков и юношей. Следует отметить, что снижение показателей $\mathrm{MOC}_{25,50,75}>15 \%$ от исходных величин также отмечалось у большинства пациентов.

У подавляющего количества больных $(94,0 \% ; p<$ $0,001)$ диагностически значимые изменения показателей ФВД были зафиксированы после ингаляции аллергена в концентрации 1000 PNU / мл.

При этом данная концентрация аллергена была решающей несколько чаще (в $96 \%$ случаев) при диагностике интермиттирующей формы БА, тогда как при персистирущем легком течении положительные результаты фиксировались при ингаляции аллергена в меньших концентрациях (12\% случаев).

Важным феноменом, возникающим при проведении ИПП с аллергеном, который необходимо фиксировать и рассматривать как положительный результат теста, является отсроченная реакция в виде возникновения симптомов бронхоспазма через

Таблица

Анализ положительных результатов ингалящионых провокационных проб с аллергенами

\begin{tabular}{|c|c|}
\hline Критерий положительных результатов & Частота фиксации, \% \\
\hline $\begin{array}{l}\text { Возникновение субъективных жалоб } \\
\text { (затрудненное дыхание, удушье, } \\
\text { приступообразный кашель) }\end{array}$ & 34,4 \\
\hline $\begin{array}{l}\text { Возникновение аускультативных признаков } \\
\text { бронхиальной обструкции }\end{array}$ & 97,4 \\
\hline \multicolumn{2}{|l|}{$\begin{array}{l}\text { Диагностически значимое (> } 15 \text { \%) } \\
\text { снижение показателей: }\end{array}$} \\
\hline $0 Ф \mathrm{~B}_{1}$ & 76,2 \\
\hline пос & 68,5 \\
\hline \multicolumn{2}{|c|}{ Снижение показателей пневмотахометрии >15 \%: } \\
\hline $\mathrm{MOC}_{25}$ & 87,3 \\
\hline $\mathrm{MOC}_{50}$ & 79,1 \\
\hline $\mathrm{MOC}_{75}$ & 89,7 \\
\hline
\end{tabular}

Примечание: $\mathrm{MOC}_{25,50,75}$ - максимальные объемные скорости выдоха на уровне 25, 50 и $75 \%$ форсированной жизненной емкости легких.
6-12 ч после ингаляции аллергена. В нашем исследовании частота подобных реакций составила $16 \%$.

Следует особо подчеркнуть, что в группе пациентов, которым проводились ИПП с аллергеном, не было отмечено ни одного случая развития тяжелых пролонгированных проявлений бронхообструктивного синдрома. Субъективные жалобы и объективные изменения, возникавшие после ингаляции аллергена, легко купировались назначением бронхолитика. При этом повторное проведение спирометрии после ингаляции $\beta_{2}$-адреномиметика этим больным позволило во всех случаях зафиксировать обратимость возникающих обструктивных изменений, что являлось дополнительным критерием для установления диагноза БА.

\section{Заключение}

1. С учетом высокой частоты атопической формы БА у подростков и юношей призывного возраста проведение специфического аллергологического обследования этой группы пациентов является обоснованным и необходимым.

2. Ингаляционные провокационные пробы с аллергенами, назначенные по показаниям и проведенные строго в соответствии с методикой их выполнения, являются информативным и безопасным методом диагностики атопической БА.

3. В диагностическом алгоритме верификации БА у подростков и юношей призывного возраста постановка ИПП с аллергенами целесообразна на этапе углубленного обследования у пациентов с нормальными показателями ФВД и выявленной специфической гиперчувствительностью.

\section{Литература}

1. Хаитов Р.М. (ред.). Клиническая аллергология: Руководство для практ. врачей. М.: Медпресс-информ; 2002.

2. Глобальная стратегия лечения и профилактики бронхиальной астмы. Интернет-источник: www. ginasthma.com

3. Горячкина Л.А., Ненашева Н.М., Гусева А.Ю. Особенности функциональной диагностики бронхиальной астмы у лиц призывного возраста. Аллергология 2002; 2: $21-26$.

4. Лунщов А.В., Скороходкина О.В. Особенности диагностики и лечения бронхиальной астмы у лиц призывного возраста. Пульмонология 2007; 4: 29-33.

5. Стандартизация легочных функциональных тестов. Официальный бюллетень Европейского респираторного общества: Пер. с англ. Пульмонология 1993; прил.

6. Frolund L., Madsen F., Scharling B. et al. Bronchial allergen challenge: dose versus concentration. Clin. Exp. Allergy 1992; 22: 219-225.

\section{Информация об авторах}

Скороходкина Олеся Валерьевна - д. м. н., проф. кафедры клинической иммунологии с аллергологией ГОУ ВПО "Казанский государственный медицинский университет Росздрава"; тел. (843) 261-74-11; e-mail: pozd-alexandr@rambler.ru

Лунцов Алексей Владимирович - к. М. н., врач аллерголог-иммунолог Гуз "Республиканская клиническая больница" МЗ РТ; тел.: (843) 268-74-62; e-mail: Lountsov@rambler.ru 